\title{
Chapter \#1
}

\section{ORGANIZATIONAL PRACTICES OF CAREER MANAGEMENT AND THRIVING AT WORK: THE MEDIATIONAL ROLE OF PSYCHOLOGICAL CAPITAL}

\author{
Julia Aubouin-Bonnaventure ${ }^{1}$, Séverine Chevalier ${ }^{1}$, Fadi Joseph Lahiani ${ }^{2}$, \\ \& Evelyne Fouquereau ${ }^{1}$ \\ ${ }^{1}$ EE 1901 QualiPsy, University of Tours, France \\ ${ }^{2}$ Cabinet AD Conseil, France
}

\begin{abstract}
In the 1980s, globalization and business competition led to an instability in work organizations which were no longer able to ensure stable and predictable careers. Responsibility of career management was then transferred to workers. Consequently, research on the role of individuals in their career management became popular, while work investigating the role of organizations gradually declined. However, some studies have indicated that it remains beneficial for organizations to invest in practices of career management (PCM) due to their link with positive outcomes for both employees and organizations, such as workers' well-being. While some studies have shown a link between PCM and indicators of hedonic well-being, work examining the links with indicators of eudemonic well-being, such as thriving at work, remains scarce. Moreover, previous studies have paid little attention to the psychological mechanisms linking PCM to well-being at work. To fill this gap, our study focused on the synergy of psychological resources (i.e., self-efficacy, hope, optimism and resilience) defined as a core construct, known as PsyCap. The sample consisted of 652 French people working in nonprofit, private and public organizations. Structural equation modeling and a bootstrapping procedure confirmed indirect effects of PCM on thriving at work through PsyCap. Limitations of the study are discussed.
\end{abstract}

Keywords: organizational practices of career management, thriving at work, psychological capital

\section{INTRODUCTION}

In the 1970s, the traditional career concept was characterized by stability, job security, and structural and vertical advancement in organizations. Ten years later, the emergence of competition brought instability into the environment of organizations that had to downsize and restructure. As a consequence, organizations were no longer able to provide structured careers with a clear and predictable linear upward trajectory and transferred responsibility for career management to workers (De Vos, Dewettinck, $\&$ Buyens, 2008). The study of the role of the individual in the management of his/her own career thus grew significantly (e.g., boundaryless careers, protean careers, kaleidoscope career) to the detriment of the role of the organization (De Vos \& Cambré, 2017).

However, there is today a need to reconsider these practices because they are essential organizational resources for workers (e.g., Clarke, 2013; Sturges, Guest, Conway, \& Davey, 2002). Specifically, these practices could be considered as signs revealing the value that organizations place on their workers by demonstrating their willingness to invest 
in their careers for the long term (Paré \& Tremblay, 2007). PCM also create a link between workers and their organization by matching their interests, inspirations and capacities with organizational possibilities. Consequently, studies have demonstrated that they are positively associated with workers' psychological health (De Vos, Dewettinck, \& Buyens, 2009) and with objective (e.g., salary and promotion) and subjective career success (e.g., career satisfaction) (Moon \& Choi, 2017; Ng, Eby, Sorensen, \& Feldman, 2005). Practices of career management (PCM) also promote individual performance such as sales (Yahya, Othman, \& Meruda, 2004). The implementation and effectiveness of these practices therefore involve substantial issues for both workers and organizations.

\section{BACKGROUND}

The field of study of PCM presents several challenges. First, there is a lack of consistency in the terms used to define them (e.g., organizational support for career development, organizational career management, traditional career management, perceived investment in worker development, prospects of career growth or development opportunities, (Baruch, Szücs, \& Gunz, 2015)). Secondly, although several typologies of practices have been developed, none are consensual (e.g., Bagdadli \& Gianecchini, 2019; Baruch \& Peiperl, 2000). Consequently, defining PCM is not easy. However, the most frequently used definition is the one proposed by $\mathrm{Ng}$ et al. (2005) who specified these practices as programs, processes, and other forms of assistance provided by organizations to support and enhance their workers' career success. These authors quote practices as diverse as training and skills development programs inside and outside the organization, skills management programs, career counseling, formal mentoring and coaching programs, individualized feedback, promotion, job rotation, outplacements, international assignments and retirement preparation programs ( $\mathrm{Ng}$ et al., 2005).

According to the Job Demands-Resources model (Demerouti, Bakker, Nachreiner, \& Schaufeli, 2001), PCM can be considered as a job resource, defined as "Physical, psychological, social, or organizational aspects of the job that may do any of the following: (a) be functional in achieving work goals, (b) reduce job demands at the associated physiological and psychological costs, (c) stimulate personal growth and development" (p. 501). These organizational practices can also be perceived as the caravan passageways of Hobfoll's Conservation of Resources theory (2011), providing the environmental conditions that support, promote, enrich and protect the resources of individuals. For example, Rego and Cunha (2009) found that these practices were positively associated with indicators of psychological health such as emotional well-being, happiness and work-family balance. Other studies have also observed positive relationships with a set of attitudes such as job satisfaction and affective engagement (Kooij, Jansen, Dikkers, \& De Lange, 2010), or positive behaviors such as organizational citizenship behaviors (Okurame, 2012). Finally, these practices have positive effects on subjective and objective indicators of career success, such as career satisfaction, promotion or wage progression ( $\mathrm{Ng}$ et al., 2005). However, few studies have investigated the relationship between PCM and heudemonic indicators of well-being. Nevertheless, several of these indicators are attracting growing interest among the scientific community, such as thriving at work (e.g., Kleine, Rudolph, \& Zacher, 2019).

Spreitzer, Sutcliffe, Dutton, Sonenshein and Grant (2005) defined thriving at work as "the psychological state in which individuals experience both a sense of vitality and a sense of learning at work" (p. 538). This definition covers two basic elements. First, the authors point out that thriving at work is a temporary state and not a durable disposition, which is 
therefore malleable. Then, they emphasize that this state comes from the combined psychological experience of vitality and learning. On the one hand, vitality refers to the feeling of having available energy and feeling alive at work. This occurs when workers feel enthusiasm for their work and are passionate about what they do. On the other hand, learning is "the acquisition and application of knowledge and skills" and is observed when workers feel that they are continuously improving in their professional activity (Porath, Spreitzer, Gibson, \& Garnett, 2012). Thriving at work is considered as a key resource for workers as it is an indicator of personal growth (Porath et al., 2012; Spreitzer et al., 2005).

For Spreitzer et al. (2005), the central premise behind their model was that "when individuals are situated in particular work contexts, they are more likely to thrive" (p. 539). Research has emphasized the need to identify the influence of organizational factors on this psychological state (e.g., Walumbwa, Muchiri, Misati, Wu, \& Meiliani, 2018). According to Demerouti et al. (2001), resources refer to the particular organizational characteristics of work that stimulate personal growth, learning and development. In this context, no study has focused specifically on the influence of PCM. However, PMC are essential for workers because they allow them to broaden their skills and knowledge, to apply them to new situations, provide them with challenges and help them develop their full potential (Armstrong-Stassen \& Stassen, 2013). We therefore hypothesized that PCM would have a positive relationship with thriving at work (hypothesis 1).

The second aim of this study was to understand the mechanism underlying this relation. According to ten Brummelhuis and Bakker (2012), organizational resources can also promote key resources, a specific kind of personal resource, which refer to management resources that facilitate the development of other resources. PsyCap can be considered in this way. Luthans and Youssef (2007) defined the latter as: an individual's positive psychological state of development that is characterized by: (1) having confidence (self-efficacy) to take on and put in the necessary effort to succeed at challenging tasks; (2) making a positive attribution (optimism) about succeeding now and in the future; (3) persevering toward goals and, when necessary, redirecting paths to goals (hope) in order to succeed; and (4) when beset by problems and adversity, sustaining and bouncing back and even beyond (resiliency) to attain success (Luthans \& Youssef, 2007, p. 334). Luthans and Youssef (2007) postulated that in theory the combination of these four personal resources generated a synergistic effect and formed the second-order factor of PsyCap. An individual with a strong sense of these four personal resources would expect good things to happen to them, make ambitious choices, perceive goals as challenges and failures as opportunities for growth (Luthans, 2002).

Several literature reviews and meta-analyses show that there is little knowledge about the organizational antecedents of PsyCap due to the lack of studies on the subject (Avey, 2014; Avey, Reichard, Luthans, \& Mhatre, 2011; Newman, Ucbasaran, Zhu, \& Hirst, 2014). However, Luthans (2002) explained that a professional environment that challenged workers and helped them to achieve their professional and personal goals would be favorable to the development of their PsyCap. In addition, PsyCap should be developed through mastery experiences and social persuasion like positive feed-back on work (Luthans, 2002). PCM represent organizational support and allow workers to plan their career, develop their skills and knowledge and advance in the hierarchy; therefore we postulated that they would promote the development of PsyCap.

Regarding the consequences of PsyCap on the individual, Youssef-Morgan and Luthans (2015) explain that these resources foster well-being because the latter is shaped by our cognitive and affective assessments. However, PsyCap is formed by positive evaluations of past, present and future events that are based on external expectations and 
positive internal capacities. The availability of PsyCap resources serves as an indicator of an overall appraisal of well-being. Numerous studies have thus demonstrated the link between PsyCap and health indicators such as job satisfaction or psychological well-being (e.g., Avey et al., 2011). More precisely, Luthans, Avolio, Avey and Norman stated in 2007 that PsyCap is a "positive appraisal of circumstances and probability for success based on motivated effort and perseverance" (p. 550). Later, Paterson, Luthans and Jeung (2014) specified that this positive appraisal leads to the adoption of agentic work behaviors. Specifically, the perception of the probability of success would influence willingness to focus on a work task. Furthermore, according to Bandura (1982), the feeling of self-efficacy would influence the choice of which activities to undertake as well as the intensity and duration of the efforts generated over time. Thus, because workers with high PsyCap would be confident in their ability to carry out tasks and to have the energy to achieve them, they would invest more in agentic behaviors. Note that agentic behaviors, such as task focus or exploration, serve as the engine of thriving at work (Spreitzer et al., 2005). Thus, PsyCap should be positively associated with thriving at work.

Very recently, Kleine et al. (2019) conducted a meta-analysis in which they found a correlation of .47 between PsyCap and thriving at work in a sample of 3,985 workers. They suggested that this link could be explained by the fact that workers are more likely to experience thriving at work when they have significant psychological capital. High psychological capital, which leads to confidence in the achievement of one's objectives and in the development of action plans, and to an increase in positive expectations and to a greater likelihood of being motivated and making long-term efforts in the professional activity, would thus increase both the learning opportunities and the vitality of the workers.

Although several studies have already identified the mediating role of PsyCap between organizational resources and dimensions of well-being (e.g., Mazzetti, Guglielmi, Chiesa, \& Mariani, 2016), to our knowledge its role linking PCM and thriving has never been tested. We therefore hypothesized that PsyCap mediated a positive relation between PCM and thriving at work (hypothesis 2).

\section{METHODS}

\subsection{Procedure}

Questionnaires were distributed in several French companies with both online and paper versions. A cover letter informed potential participants that this study was confidential and voluntary. The data were collected over approximately six weeks.

\subsection{Participants}

The sample consisted of 652 French workers of whom 524 were female $(80.4 \%)$ and 128 male $(19.6 \%)$. Their average age was 41.84 years $(\mathrm{SD}=11.01$; range 15 to 69 years) and with an average job tenure of 9.26 years $(\mathrm{SD}=9.18) .473$ participants lived with a partner and 179 were single. Regarding contracts, $82.8 \%$ were permanent and $16.8 \%$ temporary. Full-time and part-time work represented $79 \%$ and $21 \%$ respectively. There were 298 people who worked in nonprofit organizations (45.7\%), 214 in private organizations $(32.8 \%)$ and 136 in public organizations $(20.9 \%)$. Finally, $79.1 \%$ were non-managerial employees, $13.5 \%$ were middle managers and $6.9 \%$ were senior managers. 


\subsection{Measures}

Participants completed a self-report questionnaire using a five-point Likert scale ( 1 = totally disagree, $5=$ totally agree $)$.

Perceived practices of career management were assessed using a new scale (in progress; Aubouin-Bonnaventure, Fouquereau \& Chevalier) composed of 3 items (e.g., My company promotes internal mobility). Results indicated an acceptable reliability $(\alpha .71)$.

Thriving at work was assessed using the 10-item scale of Porath et al. (2012) assessing the extent to which workers experience both a sense of vitality and a sense of learning at work. More precisely, learning and vitality were assessed with five items each. Like Porath et al. (2012), we computed a composite score for these two dimensions. Results indicated an acceptable reliability ( $\alpha .89)$.

PsyCap was assessed with the short version (PCQ-12) of the Psychological Capital Questionnaire (PCQ-24) (Luthans et al., 2007). More precisely, hope was assessed with four items, self-efficacy with three items, resilience with three items and optimism with two items. Results indicated an acceptable reliability for hope $(\alpha=70)$ and self-efficacy $(\alpha=.83)$, and a relative reliability for resilience $(\alpha=.50)$ and optimism $(\alpha=.42)$.

\section{STATISTICAL ANALYSIS AND RESULTS}

First, preliminary analyses demonstrated (Table 1) that PCM was positively related to thriving at work $(r=.45, \mathrm{p}<.05)$ and to PsyCap $(r=.36, \mathrm{p}<.05)$, and that PsyCap was positively related to thriving at work $(r=.58, \mathrm{p}<.05)$

Table 1.

Means, standard deviations and correlations among the study variables.

\begin{tabular}{|c|c|c|c|c|c|c|c|c|c|c|c|c|}
\hline & & Mean & SD & 1 & 2 & 3 & 4 & 5 & 6 & 7 & 8 & 9 \\
\hline 1 & PCM & 3.59 & 0.72 & - & .36 & .18 & .33 & .41 & .18 & .45 & .44 & .39 \\
\hline 2 & PsyCap & 3.71 & 0.48 & & & .69 & .83 & .79 & .76 & .58 & .49 & .60 \\
\hline 3 & Self-efficacy & 3.87 & 0.66 & & & - & .47 & .28 & .37 & .34 & .27 & .38 \\
\hline 4 & Hope & 3.72 & 0.54 & & & & - & .60 & .55 & .59 & .51 & .58 \\
\hline 5 & Optimism & 3.50 & 0.73 & & & & & - & .48 & .51 & .44 & .51 \\
\hline 6 & Resilience & 3.75 & 0.57 & & & & & & - & .36 & .28 & .39 \\
\hline 7 & Thriving at work & 3.75 & 0.61 & & & & & & & - & .94 & .92 \\
\hline 8 & Vitality & 3.78 & 0.71 & & & & & & & & - & .72 \\
\hline 9 & Learning & 3.71 & 0.60 & & & & & & & & & _ \\
\hline
\end{tabular}

Then, we performed structural equation modeling using AMOS Version 25. The model tested consisted of three latent variables and 25 observed variables. The SEM estimates were generated with the maximum-likelihood estimation method. The goodness-of-fit indices for our model were acceptable: $\chi^{2}=824.49$ (263), p <.001, $\mathrm{CFI}=.92, \mathrm{SRMR}=.05, \mathrm{RMSEA}=.06$.

As shown in Figure 1, the results of structural equation modeling indicated that PCM was positively related to PsyCap $(\beta=.43 ; \mathrm{p}<.001)$, which was positively linked to thriving at work $(\beta=.63 ; \mathrm{p}<.001)$. The results also revealed that PCM had a direct significant positive effect on thriving at work $(\beta=.28 ; \mathrm{p}<.001)$. These results suggested an indirect effect of PCM on thriving at work through PsyCap (partial mediation). In order to assess the magnitude and significance of this indirect effect, we then adopted a bootstrap 
procedure. A confidence interval (95\%) was calculated using 5,000 generated samples. The results confirmed the indirect effect of PCM on thriving at work through PsyCap $(\beta=.27, \mathrm{SE}=.05,95 \% \mathrm{CI}=[.19$ to .38$])$.

Figure 1.

The mediation model.

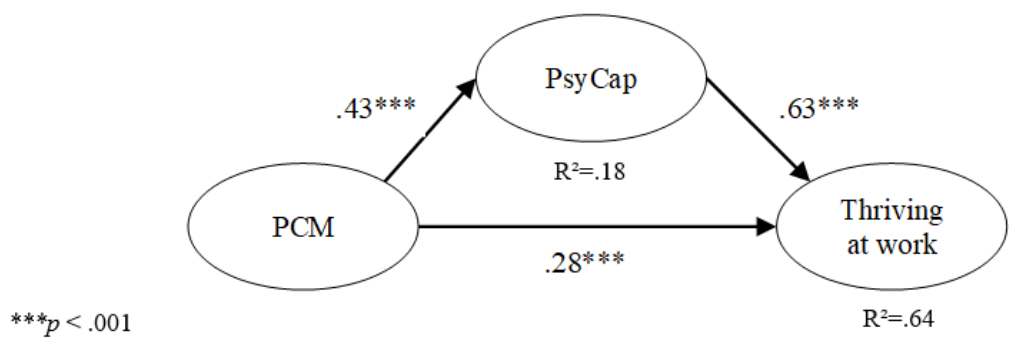

\section{DISCUSSION, LIMITATIONS AND FUTURE RESEARCH DIRECTIONS}

The aim of this study was to identify the relationship between PCM and thriving at work, and to test an underlying explanatory mechanism, particularly the mediational role of PsyCap. The results validated our hypotheses. First, PCM was positively associated with thriving at work (hypothesis 1), and secondly, this relationship was partially mediated by PsyCap (hypothesis 2). In other words, PCM provide workers with opportunities to develop their personal resources (i.e., sense of self-efficacy, hope, optimism, resilience), which in turn have the power to foster their thriving at work.

The results of this study are innovative for the scientific community in the field of organizational practices. First, while few studies have investigated the relationship between PCM and heudemonic indicators of well-being, our results demonstrate that these organizational practices facilitate workers' thriving at work. Thus, this study completes a gap in the scientific literature. Secondly, they reveal one of the mechanisms explaining this relationship. Specifically, while recent studies have demonstrated the mediating role of psychological capital between high performance work system and workers' attitudes (e.g., Agarwal \& Farndale, 2017), none have explored the link between workers' perception of PCM and their thriving at work. Thirdly, the results show that these practices promote psychological capital, thus responding to the need to identify its antecedents (Avey, 2014). Finally, the results are consistent with the theory of resource conservation (Hobfoll, 2011), which explains that the professional environment has the power to preserve and support the personal resources of workers.

This study presents two major limitations. First, participants were essentially female, and several studies have demonstrated that gender influences the perception of organizational practices and consequently their attitudinal and behavioral consequences. For example, Andersén and Andersén (2019) observed that the influence of organizational practices on affective engagement was significantly stronger for women than for men. Therefore, we recommend repeating this study with a more balanced sample. Secondly, this study used a cross-sectional protocol and it was therefore not possible to identify the 
predictive character of PCM on PsyCap and on thriving at work. Future studies should therefore use a longitudinal or even an experimental protocol in order to explore the effects of PCM on PsyCap and on thriving at work. For example, PCM could be implemented in two departments of an organization, one constituting the experimental group, and the other the control group. Measures conducted upstream and downstream of the implementation of these organizational practices would then reveal any causal link with workers' PsyCap and thriving at work.

Finally, our results revealed that PsyCap only partially mediated PCM and thriving at work, suggesting that other underlying mechanisms may explain the relationship between them, including agentic work behaviors (Niessen, Sonnentag, \& Sach, 2012), psychological contract fulfillment, or perceived organizational support (Chang \& Busser, 2020). Identification of these potential mechanisms would help understand the effects of PCM on workers' psychological health.

\section{CONCLUSION}

The results of this study demonstrate that workers' psychological health is associated with PCM. Organizations should therefore consider these practices as a focus of company policy to promote psychological health and safety in the workplace. In addition, PCM is a way of satisfying the expectations of both employees and the organization by matching the interests, ideas and capacities of the employees with organizational possibilities. Concretely, organizations should carry out regular individual interviews with their employees in order to identify their career needs and offer them advice. They should implement practices such as training programs to enable their employees to develop their skills, internal upward mobility programs, job rotation and international assignments to maintain their motivation, and retirement preparation programs to show their employees that they support them until the end of their career. Finally, organizations should conduct regular employee satisfaction surveys to determine whether these practices need to be improved.

\section{REFERENCES}

Agarwal, P., \& Farndale, E. (2017). High-performance work systems and creativity implementation: The role of psychological capital and psychological safety: High-performance work systems and creativity implementation. Human Resource Management Journal, 27(3), 440-458. doi:10.1111/1748-8583.12148

Andersén, J., \& Andersén, A. (2019). Are high-performance work systems (HPWS) appreciated by everyone? The role of management position and gender on the relationship between HPWS and affective commitment. Employee Relations: The International Journal, 41(5), 1046-1064. doi:10.1108/ER-03-2018-0080

Armstrong-Stassen, M., \& Stassen, K. (2013). Professional development, target-specific satisfaction, and older nurse retention. Career Development International, 18(7), 673-693. doi:10.1108/CDI-08-2013-0102

Avey, J. B. (2014). The Left Side of Psychological Capital: New Evidence on the Antecedents of PsyCap. Journal of Leadership \& Organizational Studies, 21(2), 141-149. doi:10.1177/1548051813515516

Avey, J. B., Reichard, R. J., Luthans, F., \& Mhatre, K. H. (2011). Meta-analysis of the impact of positive psychological capital on employee attitudes, behaviors, and performance. Human Resource Development Quarterly, 22(2), 127-152. doi:10.1002/hrdq.20070 
Bagdadli, S., \& Gianecchini, M. (2019). Organizational career management practices and objective career success: A systematic review and framework. Human Resource Management Review, 29(3), 353-370. doi:10.1016/j.hrmr.2018.08.001

Bandura, A. (1982). Self-Efficacy Mechanism in Human Agency. American Psychologist, 37(2), 122-147. doi:10.1037/0003-066X.37.2.122

Baruch, Y., \& Peiperl, M. (2000). Career management practices: An empirical survey and implications. Human Resource Management, 39(4), 347-366. doi:10.1002/1099-050X(200024)39:4<347::AID-HRM6>3.0.CO;2-C

Baruch, Y., Szücs, N., \& Gunz, H. (2015). Career studies in search of theory: The rise and rise of concepts. Career Development International, 20(1), 3-20. doi:10.1108/CDI-11-2013-0137

Chang, W., \& Busser, J. A. (2020). Hospitality career retention: The role of contextual factors and thriving at work. International Journal of Contemporary Hospitality Management, 32(1), 193-211. https://doi.org/10.1108/IJCHM-10-2018-0831

Clarke, M. (2013). The organizational career: Not dead but in need of redefinition. The International Journal of Human Resource Management, 24(4), 684-703. doi:10.1080/09585192.2012.697475

De Vos, A., \& Cambré, B. (2017). Career Management in High-Performing Organizations: A Set-Theoretic Approach: Career Management in High-Performing Organizations: A Set-Theoretic Approach. Human Resource Management, 56(3), 501-518. doi:10.1002/hrm. 21786

De Vos, A., Dewettinck, K., \& Buyens, D. (2008). To move or not to move?: The relationship between career management and preferred career moves. Employee Relations, 30(2), 156-175. doi: $10.1108 / 01425450810843348$

De Vos, A., Dewettinck, K., \& Buyens, D. (2009). The professional career on the right track: A study on the interaction between career self-management and organizational career management in explaining employee outcomes. European Journal of Work and Organizational Psychology, 18(1), 55-80. doi:10.1080/13594320801966257

Demerouti, E., Bakker, A. B., Nachreiner, F., \& Schaufeli, W. B. (2001). The job demands-resources model of burnout. Journal of Applied Psychology, 86(3), 499-512. doi:10.1037/0021-9010.86.3.499

Hobfoll, S. E. (2011). Conservation of resource caravans and engaged settings: Conservation of resource caravans. Journal of Occupational and Organizational Psychology, 84(1), 116-122. doi:10.1111/j.2044-8325.2010.02016.x

Kleine, A., Rudolph, C. W., \& Zacher, H. (2019). Thriving at work: A meta-analysis. Journal of Organizational Behavior, 40(9-10), 973-999. doi:10.1002/job.2375

Kooij, D. T. A. M., Jansen, P. G. W., Dikkers, J. S. E., \& De Lange, A. H. (2010). The influence of age on the associations between HR practices and both affective commitment and job satisfaction: A meta-analysis: HR Practices, age, and work-related attitudes. Journal of Organizational Behavior, 31(8), 1111-1136. doi:10.1002/job.666

Luthans, F. (2002). Positive organizational behavior: Developing and managing psychological strengths. Academy of Management Perspectives, 16(1), 57-72. doi:10.5465/ame.2002.6640181

Luthans, F., Avolio, B. J., Avey, J. B., \& Norman, S. M. (2007). Positive psychological capital: Measurement and relationship with performance and satisfaction. Personnel Psychology, 60(3), 541-572. doi:10.1111/j.1744-6570.2007.00083.x

Luthans, F., \& Youssef, C. M. (2007). Emerging Positive Organizational Behavior. Journal of Management, 33(3), 321-349. doi:10.1177/0149206307300814

Mazzetti, G., Guglielmi, D., Chiesa, R., \& Mariani, M. G. (2016). Happy employees in a resourceful workplace: Just a direct relationship?: A study on the mediational role of psychological capital. Career Development International, 21(7), 682-696. doi:10.1108/CDI-03-2016-0035

Moon, J. S., \& Choi, S. B. (2017). The Impact of Career Management on Organizational Commitment and the Mediating Role of Subjective Career Success: The Case of Korean R\&D Employees. Journal of Career Development, 44(3), 191-208. doi:10.1177/0894845316643829

Newman, A., Ucbasaran, D., Zhu, F., \& Hirst, G. (2014). Psychological capital: A review and synthesis. Journal of Organizational Behavior, 35, 120-138. doi:10.1002/job.1916 
Organizational Practices of Career Management and Thriving at Work: The Mediational Role of Psychological Capital

Ng, T. W. H., Eby, L. T., Sorensen, K. L., \& Feldman, D. C. (2005). Predictors of objective and subjective career success. A meta-analysis. Personnel Psychology, 58(2), 367-408. doi:10.1111/j.1744-6570.2005.00515.x

Niessen, C., Sonnentag, S., \& Sach, F. (2012). Thriving at work: A diary study [Data set]. Journal of Organizational Behavior, Vol. 33(4), 468-487. doi:10.1037/e518392013-197

Okurame, D. (2012). Impact of career growth prospects and formal mentoring on organisational citizenship behaviour. Leadership \& Organization Development Journal, 33(1), 66-85. doi:10.1108/01437731211193124

Paré, G., \& Tremblay, M. (2007). The Influence of High-Involvement Human Resources Practices, Procedural Justice, Organizational Commitment, and Citizenship Behaviors on Information Technology Professionals' Turnover Intentions. Group \& Organization Management, 32(3), 326-357. doi:10.1177/1059601106286875

Paterson, T. A., Luthans, F., \& Jeung, W. (2014). Thriving at work: Impact of psychological capital and supervisor support. Journal of Organizational Behavior, 35(3), 434-446. doi:10.1002/job.1907

Porath, C., Spreitzer, G., Gibson, C., \& Garnett, F. G. (2012). Thriving at work: Toward its measurement, construct validation, and theoretical refinement. Journal of Organizational Behavior, 33(2), 250-275. doi:10.1002/job.756

Rego, A., \& Cunha, M. P. e. (2009). Do the opportunities for learning and personal development lead to happiness? It depends on work-family conciliation. Journal of Occupational Health Psychology, 14(3), 334-348. doi:10.1037/a0014248

Spreitzer, G., Sutcliffe, K., Dutton, J., Sonenshein, S., \& Grant, A. M. (2005). A Socially Embedded Model of Thriving at Work. Organization Science, 16(5), 537-549. doi:10.1287/orsc.1050.0153

Sturges, J., Guest, D., Conway, N., \& Davey, K. M. (2002). A longitudinal study of the relationship between career management and organizational commitment among graduates in the first ten years at work. Journal of Organizational Behavior, 23(6), 731-748. doi:10.1002/job.164

ten Brummelhuis, L. L., \& Bakker, A. B. (2012). A resource perspective on the work-home interface: The work-home resources model. American Psychologist, 67(7), 545-556. doi:10.1037/a0027974

Walumbwa, F. O., Muchiri, M. K., Misati, E., Wu, C., \& Meiliani, M. (2018). Inspired to perform: A multilevel investigation of antecedents and consequences of thriving at work. Journal of Organizational Behavior, 39(3), 249-261. doi:10.1002/job.2216

Yahya, K. K., Othman, S. Z., \& Meruda, N. (2004). Relationship between organizational career management and individual performance. Analisis, 11(2), 73-90.

Youssef-Morgan, C. M., \& Luthans, F. (2015). Psychological Capital and Well-being: Psychological Capital and Well-being. Stress and Health, 31(3), 180-188. doi:10.1002/smi.2623

\section{AUTHORS' INFORMATION}

Full name: Julia Aubouin Bonnaventure

Institutional affiliation: EE 1901 QualiPsy, University of Tours (France)

Institutional address: Université de Tours, UFR Arts et Sciences Humaines, Département de psychologie, 3 rue des Tanneurs, 37041 Tours Cedex 1, France

Short biographical sketch: Julia Aubouin Bonnaventure is a $\mathrm{Ph} . \mathrm{D}$ student in work and organizational psychology at the University of Tours, under the supervision of Prof. Evelyne Fouquereau and Séverine Chevalier. Her current research focuses on the effects of organizational practices on psychological health, attitudes and behavior at work. 
Full name: Séverine Chevalier

Institutional affiliation: EE 1901 QualiPsy, University of Tours (France)

Institutional address: Université de Tours, UFR Arts et Sciences Humaines, Département de psychologie, 3 rue des Tanneurs, 37041 Tours Cedex 1, France

Short biographical sketch: Séverine Chevalier is an Associate Professor in work and organizational psychology at the University of Tours (France). Her research interests include antecedents and outcomes of well-being and psychological health at work, career management and entrepreneurship.

Full name: Fadi Joseph Lahiani

Institutional affiliation: Cabinet AD Conseil (France)

Institutional address: 7 Allée Mirabeau, 92240 Malakoff, France

Short biographical sketch: Fadi Joseph LAHIANI heads AD CONSEIL, a social and solidarity enterprise supporting private and public employers in the improvement of working conditions and contributing to applied research projects in partnership with universitary and institutional players.

Full name: Evelyne Fouquereau

Institutional affiliation: EE 1901 QualiPsy, University of Tours (France)

Institutional address: Université de Tours, UFR Arts et Sciences Humaines, Département de psychologie, 3 rue des Tanneurs, 37041 Tours Cedex 1, France

Short biographical sketch: Evelyne Fouquereau is currently full Professor and the Director of the Psychology unit, "Quality of life and psychological health" (QualiPsy, EE 1901) at the University of Tours (France). She supervises research in Psychology of Work, Organizational Psychology and Applied Psychology. Her research mainly concerns workers' psychological health in various contexts, organizational behaviors, career management, leadership at work and entrepreneurship. 